This item was submitted to Loughborough's Research Repository by the author.

Items in Figshare are protected by copyright, with all rights reserved, unless otherwise indicated.

\title{
High-speed, integrated ablation cell and dual concentric injector plasma torch for laser ablation-inductively coupled plasma mass spectrometry
}

\section{PLEASE CITE THE PUBLISHED VERSION}

http://dx.doi.org/10.1021/acs.analchem.5b02466

\section{PUBLISHER}

(C) American Chemical Society

\section{VERSION}

AM (Accepted Manuscript)

\section{PUBLISHER STATEMENT}

This work is made available according to the conditions of the Creative Commons Attribution-NonCommercialNoDerivatives 4.0 International (CC BY-NC-ND 4.0) licence. Full details of this licence are available at: https://creativecommons.org/licenses/by-nc-nd/4.0/

\section{LICENCE}

CC BY-NC-ND 4.0

\section{REPOSITORY RECORD}

Douglas, David N., Amy J. Managh, Helen J. Reid, and Barry L. Sharp. 2019. "High-speed, Integrated Ablation Cell and Dual Concentric Injector Plasma Torch for Laser Ablation-inductively Coupled Plasma Mass Spectrometry". figshare. https://hdl.handle.net/2134/19620. 


\title{
A High-Speed, Integrated Ablation Cell and Dual Concentric Injector Plasma Torch for Laser Ablation-Inductively Coupled Plasma-Mass Spectrometry
}

\author{
David N. Douglas $† \ddagger$, Amy J. Managh‡, Helen J. Reid and Barry L. Sharp* \\ The Centre for Analytical Science, The Department of Chemistry, School of Science, Loughborough University, Epinal \\ Way, Loughborough, Leicestershire, UK, LE11 3TU
}

\begin{abstract}
In recent years, laser ablation - inductively coupled plasma - mass spectrometry (LA-ICP-MS) has gained increasing importance for biological analysis, where ultra-trace imaging at micron resolution is required. However, whilst undoubtedly a valuable research tool, the washout times and sensitivity of current technology have restricted its routine and clinical application. Long periods between sampling points are required to maintain adequate spatial resolution. Additionally, temporal signal dispersion reduces the signal-to-noise ratio, which is a particular concern when analysing discrete samples, such as individual particles or cells. This paper describes a novel, two-volume laser ablation cell and integrated ICP torch designed to minimise aerosol dispersion for fast, efficient sample transport. The holistic design utilises a short, continuous diameter fused silica conduit, which extends from the point of ablation, through the ICP torch, and into the base of the plasma. This arrangement removes the requirement for a dispersive component for argon addition, and helps to keep the sample on axis with the ICP cone orifice. Hence, deposition of sample on the cones is theoretically reduced with a resulting improvement in the absolute sensitivity (counts per unit mole). The system described here achieved washouts of 1.5, 3.2 and 4.9 ms for NIST 612 glass, at full width half, 10\% and 1\% maximum respectively, with an 8 to14 fold improvement in absolute sensitivity, compared to a single volume ablation cell. To illustrate the benefits of this performance, the system was applied to a contemporary bio-analytical challenge, specifically the analysis of individual biological cells, demonstrating similar improvements in performance.
\end{abstract}

\section{INTRODUCTION}

Two important fields in which Laser Ablation-Inductively Coupled Plasma-Mass Spectrometry (LA-ICP-MS) is experiencing growing demand are those of imaging/mapping, notably of biological targets ${ }^{1-6}$ and the analysis of discrete smallvolume samples such as single cells ${ }^{7-11}$ or nanoparticulate ${ }^{12-}$ ${ }^{14}$. For example this technique has been used to investigate the etiology and pathogenesis of disease states arising from imbalances in metal homeostasis. The links between imbalances of transition metals, such as $\mathrm{Fe}, \mathrm{Zn}, \mathrm{Cu}$ and $\mathrm{Mn}$, have been investigated in brain tissue as markers for Alzheimer's disease ${ }^{15-17}$ and Parkinson's disease ${ }^{18,19}$, in retinal tissue as a factor in Age related Macular Degeneration ${ }^{20}$ and in liver to study Wilson's disease ${ }^{21}$. To differentiate regions of interest, high-spatial resolution is required on the micron scale.

Existing commercial LA-ICP-MS platforms limit the practicality of obtaining high resolution data due to long residence times of ablated particulate in the sample cell and transport tubing. Long washout times result in long analysis times when image pixels are generated from the integrated peak area of each resolved laser spot. Analysis times can be reduced by a faster sampling rate, but this leads to mixing of the ablated material from successive laser-sampling spots and requires mathematical deconvolution of the transient signal to separate data from consecutive laser pulses.. Models of the signal response from particle transport processes ${ }^{22}$ can be used to implement mathematical corrections to improve the spatial resolution ${ }^{23,24}$ but cannot fully resolve spots into discrete pixels. Over-sampling of the material can be employed to further improve spatial resolution beyond the smallest available spot size on commercial ablation systems. ${ }^{25}$ A consideration of increasingly smaller sampling areas is that if the transport efficiency and response of the instrumental detector remain constant, the inherently small mass resulting from higher spa- tial resolutions results in a poorer signal-to-noise (SN) ratio and a worse limit of detection (LOD). This can limit the applicability of LA-ICP-MS when analysing ultra-trace elements in biological materials or isotope ratios in single particles, unless an improvement in the absolute sensitivity of the system can be achieved.

Commercially available LA cells achieve washout times from $100 \%$ to $1 \%$ signal maximum in $1.5 \mathrm{~s}$ or less: ESI's TwoVol 2 and TrueLine: $<0.7$ s and $<0.25$ s respectively ${ }^{26,27}$; Teledyne Cetac Technologies' HelEx: $<0.7 \mathrm{~s}^{28}$ and the twovolume Laurin Technic cell: $<1.5 \mathrm{~s}^{29}$. A large number of LA cells have been reported from academia, these often being designed to improve measurement performance for specific sample types. Critically, there is no universal agreement on appropriate performance criteria which makes comparison difficult. LA cells for ICP-MS can be broken down into four design concepts: a closed single volume, a closed two volume, open and in-torch designs.

The single volume cell encompasses the whole sample and ejected sample-particulate can diffuse throughout the entire volume of the cell. The cell geometry is critical to performance, particularly the shape and volume, and the relative position of the inlet and outlet ports in relation to the sampling region. ${ }^{30-32}$ Horstwood et al described a tear-drop shaped single volume cell (inner volume ca $3 \mathrm{~cm}^{3}$ ) ${ }^{33}$, based on theoretical and experimental observations of particle transport by Bleiner and Günther ${ }^{22}$, which was capable of resolving single shots in $0.8 \mathrm{~s}$. A limitation of the single volume design is that the response is not uniform across the cell surface. Furthermore, the very low inner volumes required for fast washout place significant restrictions on sample size. These limitations have prompted the development of the more favorable two volume design. 
The two volume cell has an inner cell or cup that surrounds the ablation site, within the closed outer cell. Hence, the cell can accommodate larger sample sizes than possible using a low single-volume chamber, whilst the effective volume into which the ejected particulate can diffuse is minimised. In some cells, the gas inlets and outlets remain fixed relative to the inner cell/cup and the sample is moved beneath it to access new sampling areas, providing homogeneous transport efficiency across the surface. Computational modelling has been used to investigate flow uniformity of a two-volume cell for large samples, where the sample holder was positioned at different locations in the outer cell. ${ }^{34}$ Washout times were reported to be $1.3 \mathrm{~s}$ for two to three orders of magnitude decrease from signal maximum of continuous ablation, and 10.4 $\mathrm{s}$ to reach background. Other two-volume designs include the Volume Optional and Low Memory (VOLM) cell which achieved washout to $10 \%$ peak maximum in $0.4 \mathrm{~s}^{35}$, and the High Efficiency Aerosol Dispersion (HEAD) cell, which used the Venturi effect to promote extraction of of the ablated material. ${ }^{36}$ When modeled, the HEAD cell was predicted to remove $99 \%$ of ejected particles to the cell outlet in $10 \mathrm{~ms}^{37}$

Computational fluid dynamics (CFD) is gaining increasing importance in the field of ICP-MS, for instance to optimise designs prior to construction of prototype components, or to offer predictions or insight into experimental observation. Design of a LA cell from numerical simulation by Autrique et al facilitated better understanding of the aerosol transport characteristics. ${ }^{38}$ The mixing of aerosol from the laser cell with the argon make-up gas within the y-piece and transport tubing was highlighted as a source of turbulence and prolonged particle residence time. This led to the development of the Laminar Flow Reactor (LFR), which used tubing of equal diameter to that of the ICP injector tube and a custom lowdispersive connector for addition of the make-up flow. This achieved a washout to 3\% of the peak area in $140 \mathrm{~ms}$, a full width half maximum (FWHM) of $16 \mathrm{~ms}$ and $10 \%$ peak maximum in 45 ms. ${ }^{39}$ Wang et al reported an in-tube cell, where ablation took place $350 \mu \mathrm{m}$ below the transport tubing. ${ }^{40} \mathrm{Ab}-$ lated material was ejected orthogonally into the argon makeup flow through an opening in the tubing, aided by a helium sheath gas. This removed the need for a mixing y-piece, hence the full width at $10 \%$ peak maximum (FW0.1M) from single shot ablation was $30 \mathrm{~ms}$, with $99.6 \%$ of the material reported to be within the first $20 \mathrm{~ms}$ and the remaining $0.4 \%$ found in the tail of the peak up to $40-50 \mathrm{~ms}$. The concept of a single diameter transport conduit was also integral to the low volume cell recently reported by van Malderen et al. ${ }^{41}$ Connecting tubing of equal diameter to that of the cylindrical cell, was integrated into both the cell and injector of the torch (as described previously by Sharp et $a l^{42}$ and in patent application: Laser Ablation Cell and Torch System for a Compositional Analysis System, number WO2014127034, US2014227776 (A1, 2014-08-14)). This produced full widths at 1\% peak maximum (FW0.01M) of $<4.7 \pm 0.4 \mathrm{~ms}$, with removal of $99 \%$ of ablated material in $\sim 6 \mathrm{~ms}$. Unusually, the cell did not allow for addition of an argon make-up flow and utilised a very high helium gas flow, which may limit its compatibility with some ICP-MS instruments. No indication was given of the sample sizes that can be accommodated in this design.

Ablating material within an ICP torch was first reported by Liu and Horlick ${ }^{43}$; the design was based on a previously de- scribed direct sampling insert ${ }^{44}$ and achieved emission peak widths at half maximum of $0.7 \mathrm{~ms}$. Tanner and Günther later developed an in-torch ablation configuration for ICP-MS. ${ }^{45-47}$ This innovation was reported to yield baseline resolved peaks with a FWHM of $4 \mathrm{~ms}$ and reproducibility of the peak maximum of $21 \%$ RSD. This design was shown to increase the signal maximum up to 1000 times compared to the 2 s FWHM of a conventional single volume cell. This system has limited practical applicability due to the limitations on sample size; however, it remains a benchmark for the characterisation of new high-speed LA-ICP-MS interfaces.

Here we describe performance data for a LA interface based on a novel, holistic design concept where the LA cell, transport tubing and torch are integrated to provide an ultra low-volume flow path to the axis of the ICP central channel. This design was first described in patent ${ }^{48}$ and at the 2013 Winter Conference on Plasma Spectrochemistry. ${ }^{42}$ The interface improves efficiency of ion sampling into the sampler and skimmer cones whilst allowing simultaneous introduction of standards, water vapour etc. into the plasma via the annulus between the 2 concentric injectors. Through this approach both the speed of response and hence the concentration sensitivity (counts $\cdot \mathrm{s}^{-1} /$ unit concentration), and importantly the absolute mass sensitivity (counts/mole) are improved. This interface has been designed in response to demands in the emerging fields of bio-imaging and discrete sample analysis, where improvements in sample throughput, signal-to-noise ratios and absolute sensitivity are a necessity.

\section{DESIGN CONCEPT}

LA-ICP-MS Interface Design. This high-speed LA-ICPMS interface ${ }^{42}$ constitutes three major components: a LA micro-sampling cell (the Sniffer) contained within a secondary outer cell, a Dual Concentric Injector torch (DCI) and a low volume connecting conduit. The three components connect to form a single unbroken conduit from capture of the ablation plume to introduction into the ICP torch. The configuration evaluated here used a $68.5 \mathrm{~cm}$ length of fused silica $(250 \mu \mathrm{m}$ I.D.), resulting in a typical transport volume from ablation site to injection of the aerosol into the ICP of $0.04 \mathrm{~cm}^{3}$ (inclusive of Sniffer micro-chamber). The length of the tubing is largely determined by the physical constraints of coupling the UP213 LA instrument (ESI, NewWave Research Division, Montana, USA) to the Element XR mass spectrometer (Thermo Fisher Scientific, Bremen, DE), however further improvement (reduction in peak width) can be anticipated if the length of the coupling tubing can be reduced. The flow in the silica tube approximates the laminar case, however, numerical simulation by Bleiner and Bogaerts demonstrated that more complex flow patterns, with differentiated cores, are likely to be present, especially when helium is used as a transport gas. ${ }^{49}$ Whilst for pure laminar flow we expect diffusional broadening of the pulse, additional broadening mechanisms may also be present.

The Sniffer was made from a single piece of Macor ${ }^{\circledR}$ (Ceramic Substrates and Components Ltd. Isle of Wight, UK): see schematic depiction in Figure 1. The design was optimised by modelling the surrounding gas; see Flow Simulation of the Interface. Macor is a bright white material and strongly reflects illuminating light, thus to improve visualization of samples the Sniffer was dyed pink using carmine dye from Cochi- 


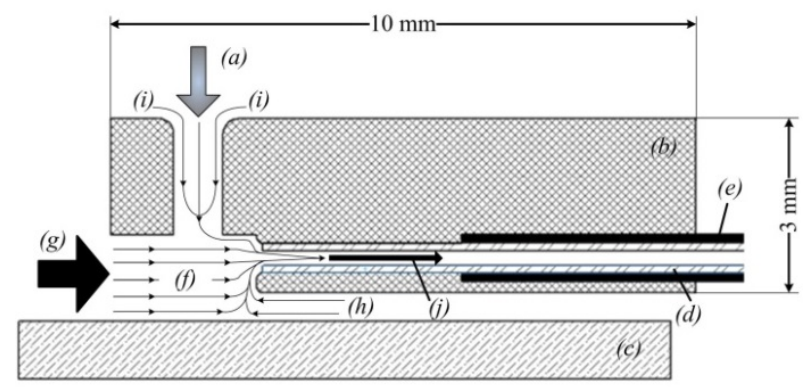

Figure 1. A schematic representation of the Sniffer cell where arrowed lines depict the direction of gas flow: (a) direction of the laser beam, (b) the Sniffer cell body, (c) the sample, (d) the fused silica transport conduit, (e) fused silica support tube, (f) the micro-chamber within which the ablation plume is contained, (g) the main bulk of gas flow entering the microchamber, (h) minor gas flow that enters the micro-chamber from beneath and (i) minor gas flow down the laser access port, (j) the laser-induced aerosol direction of travel towards the ICP.

neal (Dr Oetker, West Yorkshire, UK). A 2.5 x 2.2 x $1 \mathrm{~mm}$ micro-chamber, volume $0.0055 \mathrm{~cm}^{3}$, encapsulates the ablation plume. Gurevich and Hergenröder have detailed the stopping distances of different particle sizes from a laser-induced plasma, calculating a $2 \mathrm{~mm}$ particle cloud radius using a laser energy of $1 \mathrm{~mJ}$ induced in an ambient pressure. ${ }^{30}$ The Sniffer cell operates at a higher pressure than most cells (depending on the length of fused silica used), $c a$. $70 \mathrm{kPa}$ for the configuration described here, effectively reducing the plume expansion and reducing any particle-Sniffer wall interaction.

A laser access port, diameter $0.85 \mathrm{~mm}$, is situated in the top of the cavity of the micro-chamber and allows visualization of the sample surface and facilitates focus of the laser beam. The main bulk of transport gas (indicated by the horizontal block arrow $(g)$ in Figure 1) enters the micro-chamber via a $1 \mathrm{~mm}$ high x $2.2 \mathrm{~mm}$ wide opening: the 'Mouth'. Opposite this opening an outlet of diameter $0.82 \mathrm{~mm}$ retains the fused silica transport tubing $(250 \mu \mathrm{m}$ I.D. $68.5 \mathrm{~cm}$ length, Supelco untreated, Sigma Aldrich, Dorset, UK), such that the distance between the ablation site and outlet can be optimised. The fused silica transport conduit is located flush with the outlet in normal operation. The Sniffer is held by a support bar parallel above the sample surface; the distance between the two can be adjusted with the use of spacers. For normal operation the distance is set to between 100 and $200 \mu \mathrm{m}$. Flow simulation, see below, has shown the efficiency of particle extraction improves with decreasing gap size; however there are operational limitations to the practicality of implementing distances below $100 \mu \mathrm{m}$.

The Sniffer cell resides within a custom built circular secondary outer-cell; the 'Enterprise' cell (Delrin, Creative Machine, Washington, US), see Figure 2. The internal volume of the Enterprise is $118 \mathrm{~cm}^{3}$. The Sniffer, and subsequently the fused silica tubing outlet tube, is held static relative to the laser beam using a fixed positioning bar which is located above the sample holder perpendicular to the sample gas inlet. Samples

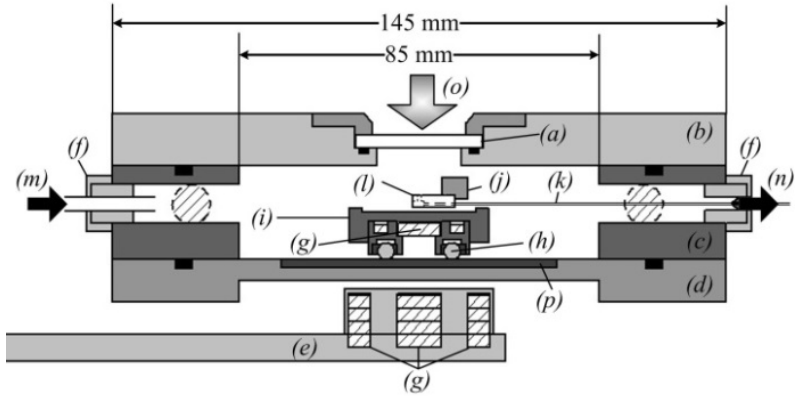

Figure 2 A Schematic representation of the Sniffer within the Enterprise cell: (a) optical window, (b) lid, (c) body, (d) base, (e) magnetic coupling stage, $(f) 1 / 8^{\text {th }}$ and $1 / 16^{\text {th }}$ gas fittings (Swagelok, Manchester, UK), (g) neodymium magnets, (h) acetal thrust rotary bearings (RS Components, Nottingham, UK), (i) sample tray, (j) Sniffer support bar, (k) fused silica transport conduit, (l) Sniffer, $(m)$ gas inlet, (n) tubing outlet to ICP and (o) direction of laser beam.

up to 25 x $25 \mathrm{~mm}$ are held upon a tray and can be moved with the aid of a magnetic (or other) coupling.

This mode of sample containment and movement relative to the static laser beam ensures that the flow geometry remains constant across the sample surface. As well as a primary gas inlet port and the transport conduit outlet, the outer cell has two additional ports that allow access for a digital pressure switch (ZSE80F-N02L-N, FTI, East Sussex, UK), and introduction of an additional gas that can be directed to specific locations within the cell, including the sniffer micro-cavity, by means of internal tubing. Only the gas inlet and the tube outlet are used during normal operation. Helium is typically used as the sample transport gas and the back pressure from the cell is measured on-line prior to the outer cell gas inlet.

The DCI required modification of the existing Element ICP torch and can be adapted for most commercial ICP-MS instruments, see Figure 3. A $1 / 2$ inch T-union (PFA, Swagelok, Manchester, UK) at the rear of the torch was mounted upon a custom built injector (Glass Expansion, Victoria, AUS) that forms the outer injector, and is used to generate a sheath flow around the uninterrupted fused silica conduit from the Sniffer cell (the fused silica becoming the inner injector). The fused silica is partially supported by borosilicate tubing and is held concentric to the outer injector by a Macor ${ }^{\circledR}$ insert (Ceramic Substrates and Components Ltd. Isle of Wight, UK). The fused silica can be retracted within or extended (up to $14 \mathrm{~mm}$ ) beyond the end of the outer injector. Argon is supplied through the shoulder of the union, typically at $1 \mathrm{Lmin}^{-1}$, to the outer injector providing a sheath gas flow that surrounds the inner injector. This facilitates punch through of the central channel in the plasma, whilst maintaining stability, and provides cooling of the inner injector during extension. The sheath gas can be used to optimise operating conditions ${ }^{50,51}$, add external aqueous/dry particle standards or to wet the plasma ${ }^{50}$. The laser-induced aerosol is contained within the He flow in the central injector and no external mixing device is required. 


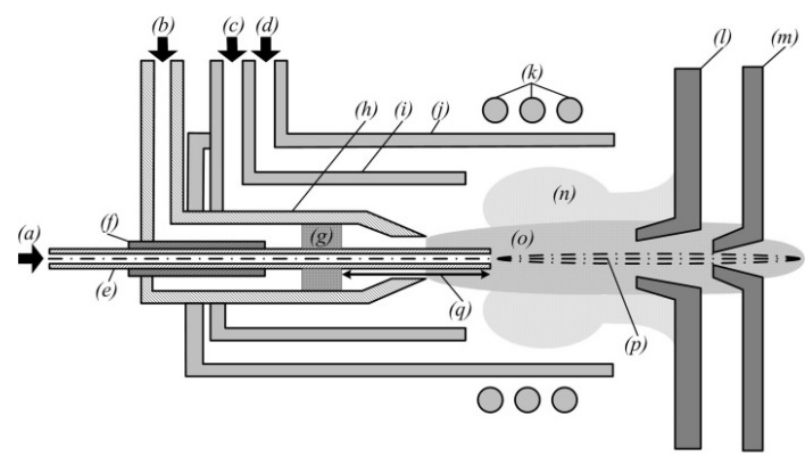

Figure 3. A schematic diagram of the DCI, representation of the plasma and the ICP-MS interface cones: (a) the aerosol direction from the Sniffer, (b) argon sheath gas, (c) argon auxiliary/plasma gas, (d) argon cool gas, (e) fused silica transport conduit (inner injector), ( $f$ ) fused silica support, $(g)$ custom Macor ${ }^{\circledR}$ centering piece, (h) outer injector, (i) auxiliary/plasma torch tube, $(j)$ outer cool torch tube, $(k)$ RF coil, (l) sampler cone, (m) skimmer cone, (n) plasma, (o) sample channel, $(p)$ likely path of laser-induced aerosol and (q) depiction of inner injector movement capability.

Flow Simulation of the Interface. 3-dimensional (3D) models of the interface components were constructed using the computer aided design (CAD) software Solidworks (Educational edition, 2011-2012, 2011 SP5.0, NT CADCAM, Worcestershire, UK). The fluid flow through the system was investigated using Solidworks' integrated flow-simulation tool-package (2011, 5.0, build 1747). This method of cell development enables investigation of multiple design concepts and iterations more cheaply than a build-and-test process. The operation of the flow simulation software has been previously described elsewhere ${ }^{52}$. In brief, a 3D mesh is created throughout the CAD model geometry to produce a series of finite cells, see Supporting Information Figure S-1. An iterative process through each cell solves Favre-averaged Navier-Stokes equations for fluid mass, momentum and energy conservation. ${ }^{53}$ The resulting model can then be used to investigate the fluid flow trajectories, local pressures and estimate the path/residence times of spherical particles injected into the flows.

The gas dynamics around the Sniffer were investigated using the addition of helium at $120 \mathrm{ml} \mathrm{min}^{-1}$, injected normal to

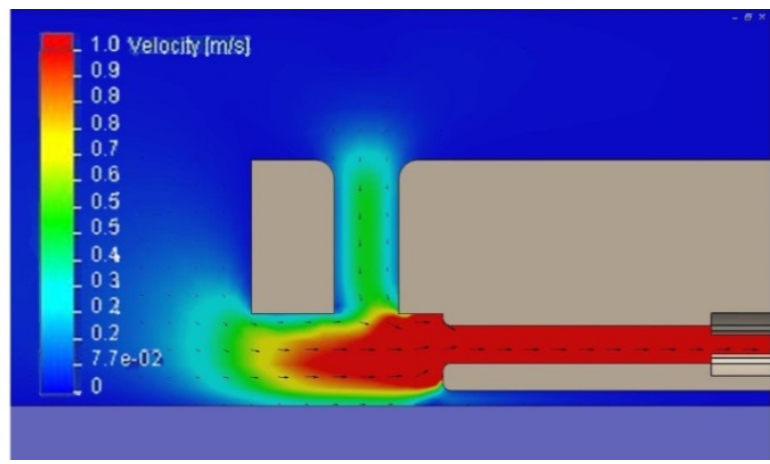

Figure 4. A cut-section of the Sniffer CAD model and gas flow, where colour contours are representative of the local gas velocities; the scale bar represents velocities from 0 to $1 \mathrm{~m} \cdot \mathrm{s}^{-1}$, from blue to red respectively. the inlet of the Enterprise cell and initially turbulent. Conditions were set to the NIST standard of $101.325 \mathrm{kPa}$ and 293.15 K. Level 5 refinement of small features (the highest permissible software setting to maximise computer memory utlisation, by minimising the number of cells for large features and maximizing that for small features) and a $0.050 \mathrm{~mm}$ minimum height of narrow channels were used to more accurately predict the flow between the gap of the Sniffer and sample surface. Data presented here are for a modelled gap distance of $200 \mu \mathrm{m}$. A total path length of $300 \mathrm{~mm}$ from the microchamber outlet to the end of fused silica transport tubing was modelled.

The modelled flow around the Sniffer, see Figure 4, provides a useful insight into the critical flow paths within the micro-chamber. The bulk of the gas flow enters the Mouth of the Sniffer (labels $f$ and $g$ in Figure 1), sweeping the sides of the micro-chamber and the surface of the sample, converging on the outlet. Rounds on the micro-chamber's exposed edges (not shown) ensure that turbulence is kept to a minimum, indicated by the lack of vortices.

Minor flows from the base of the micro-chamber closest to the outlet, label $h$ in Figure 1, aid in laser-induced particletransport by providing a lifting force into the outlet. Any flow path through the micro-chamber which travels close to the sample surface meets this counter-flow and is directed towards the outlet. This pressure in the opposed-direction of the bulk of gas flow ensures particles are retained within the microchamber. A similar effect occurs through the laser access port, where a small gas flow is observed with increased gas velocity in this localised region, indicated by annotation $i$ in Figure 1. This aids in laser-induced particle confinement to the microchamber by retarding the expansion of the aerosol plume. Detailed flow trajectories and velocities around these features are given in Supplementary Information, Figure S-2.

Spherical glass particles (standard Solidworks parameters) at a mass flow rate of $1.23 \times 10^{-10} \mathrm{~kg} \cdot \mathrm{s}^{-1}$ and diameter 10,100 and $1000 \mathrm{~nm}$ were injected into the model to investigate likely residence times within the system and any areas of potential turbulence. Particle injections were located at the sample surface with no initial velocity, as inclusion of laser induced plasma dynamics and plume expansion are beyond the capability of the software used. 12 locations within the microchamber and concentric to the laser access port were selected as injection points; see Figure 5 . The maximum spread of the locations was $0.85 \mathrm{~mm}$ (points 3 to 4 and points 5 to 8 ).

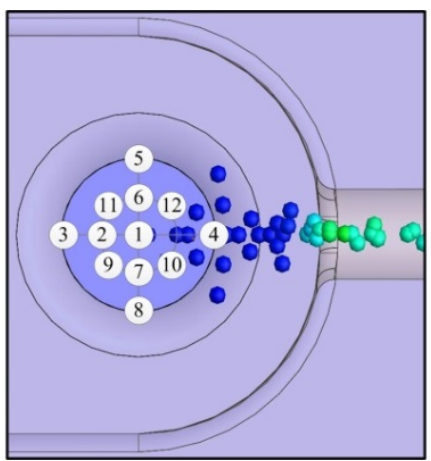

Figure 5. Cut-section of the Sniffer CAD model, view down through the laser access port towards the sample surface Particle injection points are numbered from 1 to 12 
Table 1. Particle residence time through Sniffer-DCI interface and maximum velocity when exiting DCI tip

\begin{tabular}{llll}
\hline Particle diameter $(\mathbf{n m})$ & $\mathbf{1 0}$ & $\mathbf{1 0 0}$ & $\mathbf{1 0 0 0}$ \\
\hline Minimum residence time (ms) & 2.80 & 2.80 & 6.10 \\
Maximum residence time (ms) & 11.0 & 10.7 & 8.40 \\
Average velocity $\left(\mathrm{m} \cdot \mathrm{s}^{-1}\right)$ & 34.6 & 35.8 & 49.9 \\
\hline
\end{tabular}

The difference between minimum and maximum particle residence times was $8.2,7.9$ and $2.3 \mathrm{~ms}$ for 10,100 and 1000 $\mathrm{nm}$ particles respectively, see Table 1 . Due to the increased susceptibility to variation from small changes in gas flow, particles of $10 \mathrm{~nm}$ showed the largest spread, and the longest residence time of $11 \mathrm{~ms}$. More comprehensive modeling of the interface, including the ICP and interface, will be undertaken at a later date.

\section{EXPERIMENTAL}

Peak Profiling Sample. LA cells are conventionally characterized by monitoring the ${ }^{238} \mathrm{U}$ signal from ablation of one or more of the NIST reference glass series. Here the reference material SRM $612\left(50 \mu \mathrm{g} \mathrm{g}^{-1}\right.$ nominal concentration, NIST, Maryland, US) was used in peak profiling experiments. The higher concentration glass SRM 610 could not be used to monitor ${ }^{238} \mathrm{U}\left(461.5 \mu \mathrm{g} \mathrm{g}^{-1}\right)$ due to the signal intensity saturating the detector in counting mode, which also occurred when trying to monitor the less abundant isotope of ${ }^{235} \mathrm{U}$ in the same material. All sampling sites were pre-ablated (60 shots) to reduce unfavorable particle size related effects with initial downhole ablation as described previously ${ }^{54}$ and a new ablation site selected and conditioned for each parameter investigated.

Instrumentation. A support bracket facilitated mounting of the Enterprise cell to a UP213 laser ablation system. Alignment of the laser access port was achieved using a manual X, Y, Z stage (Edmund Optics, Yorkshire, UK). The laser operating conditions are given in Table 2. Two laser beam spot sizes $(6$ and $8 \mu \mathrm{m})$ and three fluence levels $(12.8,17.2$ and 22.1 $\mathrm{J} \cdot \mathrm{cm}^{-2}$ ) were used to investigate sample loading. At a laser spot diameter of $6 \mu \mathrm{m}$, fluences above $22.1 \mathrm{~J} \cdot \mathrm{cm}^{-2}$ yielded a mass flow that resulted in detector saturation when monitoring ${ }^{238} \mathrm{U}$. Ablation conditions could not be fully optimised to achieve best shot-to-shot reproducibility, which are normally found at higher laser fluence. Due to laser energy instability (a significant factor for this older design laser) peak profile reproducibility was significantly worse at fluences below $12.8 \mathrm{~J} \cdot \mathrm{cm}^{-2}$.

A safe working limit of $100 \mathrm{k} \cdot$ Pa pressure within the cell was imposed based upon the outer cell materials and fixings. A flow rate of $125 \mathrm{ml} \mathrm{min}^{-1}$ resulted in a pressure within the cell of $70 \mathrm{kPa}$. No significant benefit in sensitivity or peak width was observed above this gas flow rate. The Zircon cell, which is an exceptionally good single-volume cell, ${ }^{33}$ described by Horstwood et al, was used as a benchmark against which to compare the interface. In this configuration an argon carrier gas was added via a y-piece to the laser-induced aerosol, downstream of the cell; total path length was $c a 90 \mathrm{~cm}$.

The DCI was connected to the semi-demountable torch (Glass Expansion, Victoria, AU) of an Element XR ICP-MS
Table 2. Characterisation of DCI-Sniffer and comparison against conventional LA-ICP-MS System - operating parameters

\begin{tabular}{|c|c|c|}
\hline UP213 Laser System & DCI-Sniffer & Zircon Cell \\
\hline Spot diameter $(\mu \mathrm{m})$ & \multicolumn{2}{|c|}{6 and 8} \\
\hline \multirow[t]{2}{*}{ Repetition rate (Hz) } & 2 & 1 \\
\hline & \multicolumn{2}{|c|}{$12.8[50 \%]$} \\
\hline \multirow{2}{*}{$\begin{array}{l}\text { Fluence }\left(\mathrm{J} \cdot \mathrm{cm}^{-2}\right)[\% \text { of max. out- } \\
\text { put }]\end{array}$} & \multicolumn{2}{|c|}{$17.2[60 \%]$} \\
\hline & \multicolumn{2}{|c|}{$22.1[70 \%]$} \\
\hline Helium sample gas flow $\left(\mathrm{ml} \cdot \mathrm{min}^{-1}\right)$ & 125 & 800 \\
\hline \multicolumn{3}{|l|}{ Element XR ICP-MS } \\
\hline Cool gas $\left(\mathrm{L} \cdot \mathrm{min}^{-1}\right)$ & \multicolumn{2}{|c|}{15.5} \\
\hline Auxiliary/plasma gas $\left(\mathrm{L} \cdot \mathrm{min}^{-1}\right)$ & \multicolumn{2}{|c|}{0.95} \\
\hline Sheath gas $\left(\mathrm{L} \cdot \mathrm{min}^{-1}\right)$ & 1.3 to 1.4 & 0.9 \\
\hline Torch Z-position (mm) & - 2.0 to -2.2 & -1.1 \\
\hline RF power (W) & $\begin{array}{c}1200 \text { to } \\
1250\end{array}$ & 1270 \\
\hline Isotope monitored & \multicolumn{2}{|c|}{${ }^{238} \mathrm{U}$} \\
\hline Resolution & \multicolumn{2}{|c|}{ Low } \\
\hline Mass window & \multicolumn{2}{|c|}{$20 \%$} \\
\hline Sample time & $0.1 \mathrm{~ms}$ & $10 \mathrm{~ms}$ \\
\hline Samples per peak & \multicolumn{2}{|c|}{1000} \\
\hline Detection mode & \multicolumn{2}{|c|}{ Counting } \\
\hline Segment duration & $20 \mathrm{~ms}$ & $2000 \mathrm{~ms}$ \\
\hline
\end{tabular}

instrument. The effects of different positions of the inner injector were investigated; the position of the inner injector tip is given relative to the tip of the static outer injector. Positive numbers indicate an extension of the inner injector into the plasma and towards the cones, whilst negative numbers are a movement of the inner injector back into the outer injector and away from the cones.

The ICP torch $\mathrm{X}, \mathrm{Y}$ and $\mathrm{Z}$ positions, the sheath gas flow and the RF power parameters were optimised for maximum peak height and area at each DCI injector position. The typical ICP operating parameters are given in Table 2 and as a range for variable conditions.

Peak Profiling Data Acquisition and Processing. Due to hardware/software limitations of the Element XR data acquisition, the short pulse duration and the efficiency of the interface, a previously reported data acquisition strategy was employed. ${ }^{55}$ In brief, the MS was operated at low resolution, this yields trapezoidal peak shapes. 1000 'samples-per-peak' were selected with a mass window of $20 \%$ to yield 200 sampling points across the flat-top portion of the mass-to-charge response peak. In counting mode the integration time for each sample is limited to $100 \mu \mathrm{s}$. Thus scanning across the peak's flat top using the settings described yields a $20 \mathrm{~ms}$ window in which to capture the response of the laser-induced aerosol with $100 \mu$ s time resolution. Data captured in this manner were exported as a .csv file. A custom macro was compiled to discard any peak where signal intensity above background occurred within 5 integrations (samples) of the start or the end of 

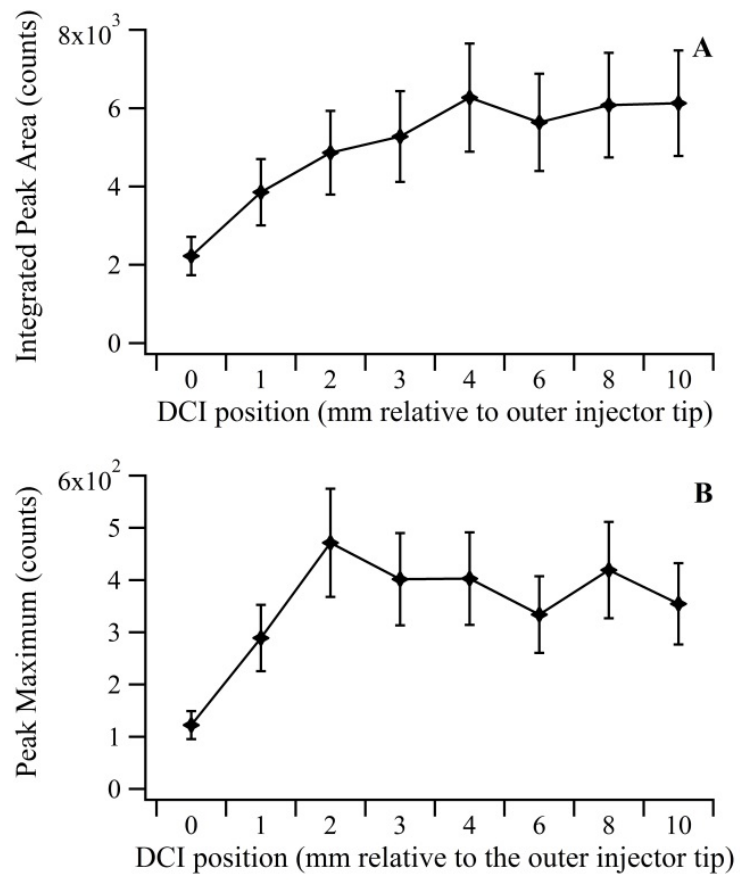

Chart 1. A: integrated peak area (counts) and B: peak maximum (counts), for DCI extensions from 0 to $10 \mathrm{~mm}$ (region of interest) using a fluence of $22.1 \mathrm{Jcm}^{-2}$ for ${ }^{238} \mathrm{U}$

the 20 ms window. In this manner partially captured peaks could be removed. A similar monitoring procedure was used for the Zircon cell; however the integration time per sample was increased to $10 \mathrm{~ms}$ to yield a time window of $2000 \mathrm{~ms}$ in duration to ensure capture of the entire peak profile.

The average peak maximum and peak area were calculated from the mean of individual peaks (minimum $\mathrm{N}=30$ ). The signal-to-background $(S / B)$ ratio was calculated by dividing the average peak maximum by the background. Alternatively the signal-to-noise ratio may be estimated by dividing the average peak maximum by the square root of the average background, assuming the data are Poisson distributed. Individual peak profiles were averaged (minimum $\mathrm{N}=30$ ) to obtain a representative peak profile for a particular set of parameters and cell. Using Igor Pro (version 6.3.6.4, WaveMetrics Inc., Oregon, USA) and the Multipeak Fitting function, curve functions were applied to the representative peak responses and used to determine the FWHM, FW0.1M and the FW0.01M.

Preparation and Analysis of Gd Labelled Cells. Human $\mathrm{CD} 4^{+} \mathrm{CD} 25^{+} \mathrm{CD} 127^{\text {lo }} \mathrm{T}$ cells were isolated from a leukocyte cone, purified to $98.5 \%$ purity, and labelled using Gd-DTPABMA (Omniscan ${ }^{\circledR}$, GE Healthcare, UK), as described previously. $^{8}$ The Gd uptake was previously determined to be $5.08 \mathrm{x}$ $10^{7}$ atoms per cell. ${ }^{8}$ Cells were prepared for laser ablation by plating onto slides (Thermo Superfrost, Thermo Scientific, UK) using a CytoSpin (Shandon Cytospin ${ }^{\circledR}$, Thermo Scientific, UK). Single shot laser ablation was performed on individual $\mathrm{T}$ cells using a $30 \mu \mathrm{m}$ spot size and a fluence of 6.40 $\mathrm{J} / \mathrm{cm}^{2}$. Only single cells were targeted; cells present in clusters or spaced at intervals of less than $30 \mu \mathrm{m}$ were ignored.

\section{RESULTS AND DISCUSSION}

Peak Profile from NIST 612 Glass. Absolute sensitivity for ${ }^{238}$ Uwas found to be independent of DCI inner injector position, with the exception of the $0 \mathrm{~mm}$ position where a significant decrease was observed. This was followed by a gradual rise and plateau (to the same absolute sensitivity observed at the $-20 \mathrm{~mm}$ position) as the DCI was extended, see Chart $1 \mathrm{~A}$. Computational modelling by Lindner et al ${ }^{56,57}$ described a turbulent mixing region of sample (outer injector sheath gas in this instance) and plasma gas immediately after the tip of the ICP injector. Extending the DCI inner injector into this region possibly further-increases turbulence and mixing of the sample gas with the plasma gas. Thus the sample aerosol may follow non-optimum flow paths when directly introduced into this region, resulting in particle loss. An increase in absolute sensitivity was expected when extending the DCI past the turbulent mixing region. However, it was observed that due to the mechanical design and the fused silica being stored as a coil, the further the DCI was extended, the less concentric it became relative to the outer injector. It can thus be inferred that during operation extension of the inner injector resulted in an off-axis alignment of the injector relative to the ICP cones. In spite of this alignment deviation the DCI was extended and operated a full $10 \mathrm{~mm}$ past the outer injector and into the plasma, with no deterioration of the fused silica tubing observed.

Similar lower absolute sensitivities at the $0 \mathrm{~mm}$ position for ${ }^{238} \mathrm{U}$ were observed at fluences of 12.8 and $17.2 \mathrm{~J} \cdot \mathrm{cm}^{-2}$, but these were less significant due to a decrease in peak area reproducibility, 37 and 25\% respectively; most likely due to non-optimum ablation conditions. This trend was consistent when increasing the mass load with a larger spot size $(8 \mu \mathrm{m})$ whilst maintaining the fluence at $12.8 \mathrm{~J} \cdot \mathrm{cm}^{-2}$ (larger spot sizes and higher fluences could not be investigated due to detector saturation). Using an $8 \mu \mathrm{m}$ spot, the peak area at the $0 \mathrm{~mm}$ position was much lower than that at the other positions, with the difference being more significant than that observed with a $6 \mu \mathrm{m}$ spot. The variance between the other extensions was significantly reduced, to 7\% RSD, due to an improved reproducibility in peak area at $8 \mu \mathrm{m}$ spot diameter (19 \% RSD).

At a fluence of $22.1 \mathrm{~J} \cdot \mathrm{cm}^{-2}$ the average peak area (excluding $0 \mathrm{~mm}$ data) for ${ }^{238} \mathrm{U}$ was found to be 5827 counts, with a $10.2 \%$ RSD between positions and a $22 \%$ RSD peak area reproducibility. When compared to the single volume Zircon cell, ${ }^{238} \mathrm{U}$ total absolute sensitivity increased 14,9 , and 8 times for fluences of $12.8,17.2$ and $22.1 \mathrm{~J} \cdot \mathrm{cm}^{-2}$ respectively. The extent of the increase is likely to be sample-specific (as demonstrated in the Gd experiments below), requiring optimisation of volumetric cell flow rate and DCI extension for different elements and matrics. The differences observed between fluences are indicative of an effect resulting from mass loading in the aerosol/vapour stream. Whether this is due to a change in particle size distribution, increased transport losses or mass loading of the plasma, is not discernable from this data.

The peak maximum followed a similar trend to that of the peak area. Comparing fluences of $22.1 \mathrm{~J} \cdot \mathrm{cm}^{-2}$ and $12.8 \mathrm{~J} \cdot \mathrm{cm}^{-2}$ for an $8 \mu \mathrm{m}$ spot, monitoring ${ }^{238} \mathrm{U}$, a significantly lower peak maximum was observed at $0 \mathrm{~mm}$, see Chart $1 \mathrm{~B}$. A peak maximum of $4.7 \times 10^{2}$ counts. (21\% RSD) was observed at the 2 


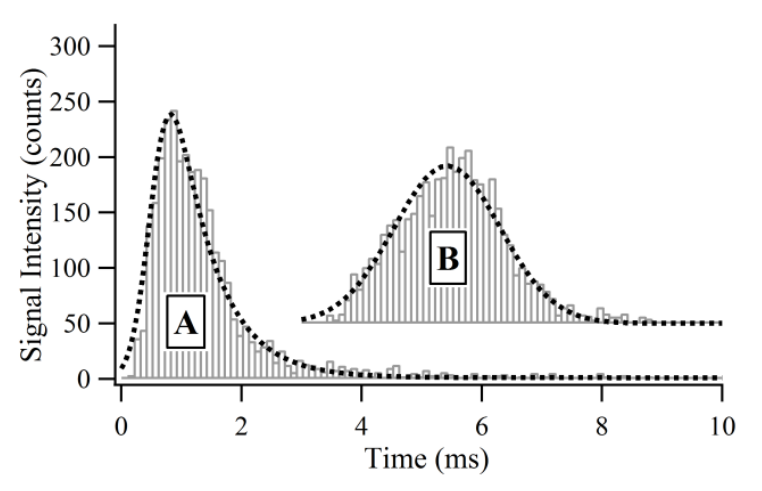

Chart 2. Example individual transient peak profiles (grey bars, segments representing the counts obtained in individual $100 \mu$ s integrations for both peaks) and fitted functions (black dotted lines) at a fluence of $22.1 \mathrm{~J} \cdot \mathrm{cm}-2$, spot diameter of $6 \mu \mathrm{m}$ and a DCI extension of $2 \mathrm{~mm}$ for ${ }^{238} \mathrm{U}$. A: peak shape fitted with an exponentially modified Gaussian function, B: peak shape fitted with a Gaussian function (off-set by $3 \mathrm{~ms}$ in the $\mathrm{x}$-axis and 50 counts in the $y$-axis for clarity)

mm extension. The peak maximum of the DCI-Sniffer was compared to that of the Zircon cell in counts $\cdot \mathrm{s}^{-1}$. The peak maximum was defined by a single integration period which is an average representation of the underlying processes within that time period. As a different sample time per integration was used to profile the DCI-Sniffer and the Zircon cell, 0.1 and $10 \mathrm{~ms}$ respectively, the signal intensities, counts $\cdot \mathrm{s}^{-1}$, were directly compared for a notional $0.1 \mathrm{~ms}$ time period. A 500, 300 and 400 fold increase in the peak maximum was observed when compared to the single volume Zircon cell for fluences of $12.8,17.2$ and $22.1 \mathrm{~J} \cdot \mathrm{cm}^{-2}$ respectively.

The Element XR has a detector electronic cut-off threshold of $5 \times 10^{6}$ counts $\mathrm{s}^{-1}$ before saturation occurs. A significant number of ${ }^{238} \mathrm{U}$ peak profiles at extensions of 2-10 mm could not be included in peak profiling due to saturation of the detector. Thus in this implementation, the DCI-Sniffer interface applicability is currently limited to small spot sizes or low concentration elements for NIST glass. Further work on improving the Element XR detection (speed and saturation limit) will be used to overcome these limitations and demonstrate the interface at full capability, whilst facilitating better investigation of the interface performance e.g. with respect to mass loading affects. It must also be noted that the optimum positions of peak area and maximum were found for uranium using an Element XR, and that other DCI positions may be optimum for other elements or ICP instrument designs.

The representative peak response associated with a particular set of operating parameters was obtained by averaging individual peaks $(\mathrm{N}>30)$, and fitting an appropriate function to the data. The typical peak shape associated with laser ablation single pulse data is Log-Normal, with an initial sharpincrease (wash-in), followed by an exponential decay in signal intensity (wash-out). However, with the DCI-Sniffer as well as observing this peak profile, as shown in Chart 2 peak A, using the same conditions and within the same analysis, individual peaks more Gaussian in shape were also randomly observed, peak B. Chi-squared values were used as a guide to the function of best fit. The tendency towards Gaussian shaped peaks increased as both the fluence was increased and the DCI was extended into the plasma, towards the ICP-MS cones. Peak shape is indicative of the flow processes occurring through the interface. With low sample loading, short residence time and a quasi-laminar/laminar flow path, the log-normal signal profile would be expected. The occurrence of Gaussian peaks indicates that diffusion is becoming significant in determining peak shape. Increased sample loading at higher fluences creates higher mass loading and greater concentration gradients, leading to higher rates of diffusion of the sample in the carrier gas. This may also explain the occurrence of some random Gaussian peaks in otherwise log-normal data sets, which may represent higher fluence-mass loading and/or changed particle sizes as a result of laser instability. To the best of the authors' knowledge Gaussian shaped peaks have not previously been experimentally observed with LA-ICP-MS. The increased occurrence of Gaussian peaks was not expected and more work is required to explain this. Some peak splitting was infrequently observed and is discussed below.

When averaging the individual peak profiles the resulting representative peak response was found to be a convolution between Gaussian and an exponential decay curve, see Chart 3 A. An exponentially modified Gaussian fit function was thus applied to the representative peak response as described for chromatography peaks by Lan et al. ${ }^{58}$ The representative peak response from the Zircon cell was fitted with an exponentially modified Gaussian function for consistency of comparison, see Chart 3 B.

At a fluence of $22.1 \mathrm{~J} \cdot \mathrm{cm}^{-2}$ and DCI position of $2 \mathrm{~mm}$ the FWHM, FW0.1M and FW0.01M of the peak response from DCI-Sniffer interface were found to be $1.5,3.2$ and $4.9 \mathrm{~ms}$ respectively for ${ }^{238} \mathrm{U}$. The range of washout times for NIST 612 particulate from the DCI-Sniffer interface at all extension and fluences investigated are given in Table 3. Peak width variation related to DCI position was only observed at the lowest fluence of $12.8 \mathrm{~J} \cdot \mathrm{cm}^{-2}$ and showed longer residence times at the -20 and $0 \mathrm{~mm}$ position. This may be related to particle formation at lower fluence for nano-second laser-pulse widths, where thermal mechanisms result in splash/melt ejection and a larger particle size distribution ${ }^{59-61}$.

Table 3. Range of FWHM, FW0.1M and FW0.01M washout times of DCI-Sniffer Interface

\begin{tabular}{llll}
\hline & \multicolumn{3}{c}{ Fluence $\left(\mathrm{J} \cdot \mathrm{cm}^{-2}\right)$} \\
& 12.8 & 17.2 & 22.1 \\
\hline FWHM (ms) & $1.4-2.7$ & $1.4-2.3$ & $1.4-2.0$ \\
FW0.1M (ms) & $4.3-5.7$ & $3.3-4.9$ & $2.9-4.4$ \\
FW0.01M (ms) & $5.9-8.9$ & $4.4-10.6$ & $4.3-9.8$
\end{tabular}


After the peak has decayed, as evidenced by the frequent occurrence of zero $100 \mu$ s count periods, there is a period of $\sim 8 \mathrm{~ms}$ during which small numbers of counting events occur stochastically, some of which can be seen in Chart $3 \mathrm{~A}$, and as reported by Van Malderen et al $^{41}$. It has been observed that in some instances these events also occur a few integration periods prior to the start of the peak. These events comprise between 1-3 consecutive $100 \mu$ s periods in which between 1-3 counts are recorded. The origins of these are not clear but they have little importance in terms of current usage of the system. They are perhaps indicative of the new kinds of observations that will become apparent as fast, high sensitivity cells come into wider use. Whilst we can scale positive counts to the time period of acquisition to give potentially significant count rates, we cannot scale zeros or differentiate them from the gas blank which also shows some random counting events. If we had a hypothetical instrument with 100\% detection efficiency we would be able to see more clearly the processes involved, but we would be placing even greater demands on the detector which, due to its limited counting rate, is already a limiting factor in system performance. Similar consideration could be applied to the effect of increasing sample size on peak width. Although this cell operates at elevated pressure, there is bound to be plume expansion and diffusion processes occurring when increasingly large amounts of material are ablated and confined to small volumes and therefore some peak broadening is to be expected, ${ }^{62}$ but we are unable to study this due to limitations in our current measurement system. Fast, high sensitivity cells are not general purpose devices and in this sense NIST glasses are not sensible test samples, but they are the benchmark material against which LA cells tend to be compared. High performance LA cells are best suited to bio-imaging, single cell or nano-particle detection/analysis where their capabilities are fully exploited.

The rare occurrence of events $>10 \mathrm{~ms}$ after the main peak can also be seen in Chart $3 \mathrm{~A}$ and are the product of spikes (single integration events) observed for 1-2 laser pulses averaged over the 30 pulses. Within the raw peak data, these are often found to be greater than or equal to than the main peak maximum. These random events are most likely the liberation of single or clusters of particles trapped within the non-ideal interface junctions.

Application to Single Cell Analysis. The performance of the system was evaluated in relation to a contemporary analytical challenge; namely the analysis of single biological cells. It was recently reported that therapeutic cells can be individually tracked in recipients through a combination of elemental labelling and LA-ICP-MS detection. ${ }^{8}$ Such monitoring is critical to the evaluation and progression of new cell-based therapies. However, vast improvements to the throughput of commercial technology are required before the technique can be implemented for routine monitoring in a clinical setting.

Regulatory T cells containing $\sim 5 \times 10^{7}$ atoms of Gd per cell ${ }^{8}$ were ablated on an individual basis. Representative peak profiles for this analysis, monitoring ${ }^{157} \mathrm{Gd}$, are depicted in Chart
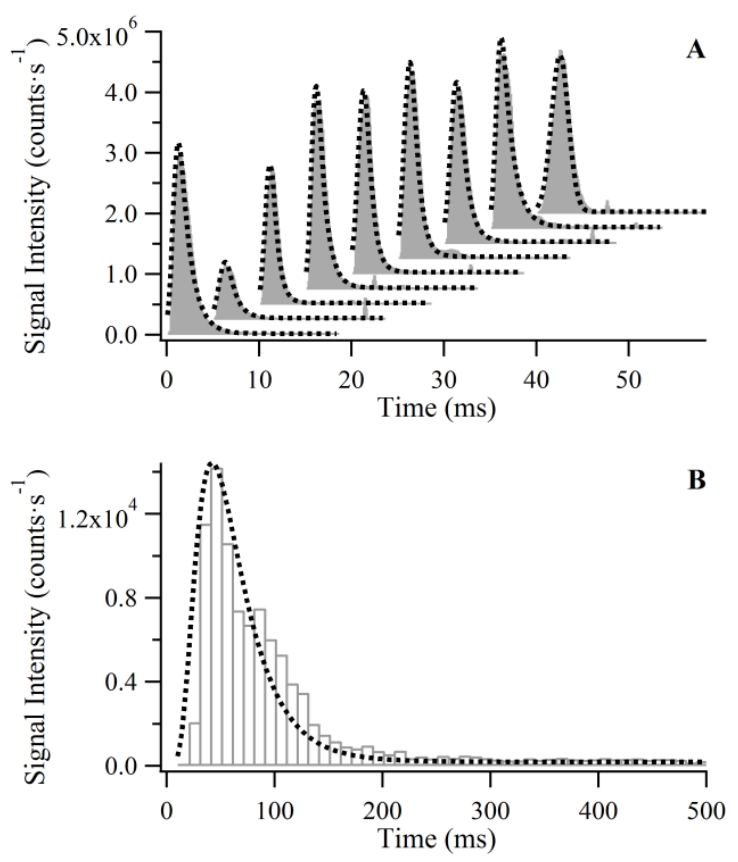

Chart 3. Representative peak response for NIST 612 monitoring ${ }^{238} \mathrm{U}$ A: DCI-Sniffer interface, grey bars are experimental data and black dotted lines are corresponding exponentially modified Gaussian fit function, moving left to right $-20,0,1,2,3,4,6,8$ and $10 \mathrm{~mm}$ positions, peaks offset of $5 \mathrm{~ms}$ in the $x$-axis and $2.5 \times 10^{5}$ cps in the $y$-axis are used for clarity. B: Zircon cell, where experimental data is represented as grey bars and the exponentially modified Gaussian fit function as the black dotted line.

4. Peak shapes were marginally broader than those observed for NIST glass, which may be a product of increased loading from the $30 \mu \mathrm{m}$ spot size and/or expansion of the predominately water-based plume in the plasma. The peak profiles were also characterised by slight peak splitting towards the longer injector extensions. Splitting was also observed by Tanner et al. during in-torch ablation, where the effect was attributed to two overlapping functions; ${ }^{46}$ a result of particle separation during formation and expansion of the laser induced aerosol. To account for this profile, two separate fit functions were applied to determine the peak width: a linear peak rise and an exponential decay. Differences between each extension were not statistically significant, due to the small sample size and the inherent variability of biological samples. However, when monitoring ${ }^{157} \mathrm{Gd}$, all extensions produced peaks of less than $10 \mathrm{~ms}$ at FW0.1M, with a range of 4.1 to $7.7 \mathrm{~ms}$ and a mean of $6.0 \mathrm{~ms}$. This is considered the most relevant peak characteristic for the cell tracking application described, since signals below the $10 \%$ level would typically be below the threshold for discriminating a labelled cell. The results therefore indicate that cell analysis rates of 100 cells per second and above are attainable, which would take the speed of LA-ICP-MS to a more clinically acceptable level. 


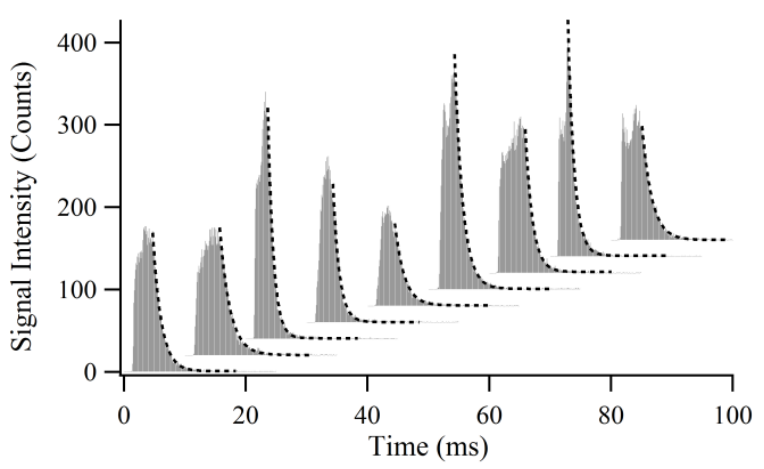

Chart 4. Representative peak response for single cell, monitoring ${ }^{157} \mathrm{Gd}$, with the inner injector extended $0,1,2,3,4$, $6,8,10$ and $12 \mathrm{~mm}$ (from left to right) past the tip of the outer injector. Each peak is representative of the averaged profile of $5 \mathrm{Gd}$ labelled cells. Signals are offset by 10 $\mathrm{ms}$ in the $\mathrm{x}$ direction and 20 counts in the $\mathrm{y}$ direction, to aid clarity.

Improvements in instrumental sensitivity are evidently beneficial for measurement of small sample sizes, such as the ones described here. On average, monitoring ${ }^{157} \mathrm{Gd}$, the prototype system delivered a 4-fold increase in absolute sensitivity compared to the Zircon cell when used for $\mathrm{T}$ cell analysis, with a 6-fold increase observed at the $6 \mathrm{~mm}$ injector extension, see Table 4 for details of H15 mean (robust statistics, $n=50$ ) of counts per cell. Assuming that there is no net loss of label during cell division, this improvement could permit tracking of a further 1-2 cell divisions than was previously possible, and hence may extend the therapeutic monitoring window.

\section{CONCLUSION}

When compared to existing technology, the holistic LA interface presented shows clear performance improvements and significant advantages, important for small/discrete sample analysis. Resolved single-shot peak widths of 1.4, 2.9 and 4.3 ms (FWHM, FW0.1M and FW0.01M respectively) were achieved when ablating NIST SRM reference glass 612 with a $6 \mu \mathrm{m}$ spot at a fluence of $22.1 \mathrm{~J} \cdot \mathrm{cm}^{-2}$. Peak widths were independent of the extension depth of the inner injector, however further work will increase time resolution of MS detection,

Table 4. H15 mean (Robust Statistics, $n=50$ ) of integrated peak area (counts) monitoring ${ }^{157} \mathrm{Gd}$ for single ablation events from single cell analysis at varied DCI extensions

\begin{tabular}{cc}
\hline DCI extension (mm) & $\begin{array}{c}\text { H15 mean } \pm \text { H15 standard deviation } \\
\text { (counts) }\end{array}$ \\
\hline 0 & $9214 \pm 4733$ \\
1 & $9879 \pm 4476$ \\
2 & $8861 \pm 4233$ \\
3 & $8575 \pm 4109$ \\
4 & $4940 \pm 2079$ \\
6 & $11934 \pm 5088$ \\
8 & $8461 \pm 3108$ \\
10 & $6440 \pm 2226$ \\
12 & $7961 \pm 3041$ \\
Zircon cell & $2159 \pm 974$
\end{tabular}

enabling better evaluation of any subtle differences between extensions. Thus this interface can theoretically be used to capture resolved single-shot data for this mass loading at a 233 $\mathrm{Hz}$ or $345 \mathrm{~Hz}$ repetition rate (dependent on the washout criteria required). For single cell analysis, where spot size was 30 $\mu \mathrm{m}$, the mean FW0.1M increased to $6.0 \mathrm{~ms}$, such that resolved data could theoretically be captured at $167 \mathrm{~Hz}$ repetition rate. Further work is required to fully evaluate mass loading effects and influence of matrix on peak width.

Compared to a good single-volume cell, a 300 to 500 fold increase in peak maximum (with no apparent increase in background), and 8 to 14 fold increase in peak area were observed for NIST SRM 612. Single cell analysis showed a 4-6 fold increase in absolute sensitivity. Increase in sensitivity (peak maximum) and total transport efficiency (inclusive of transit through the plasma) thus increases the applicability of LA to imaging and discrete sample analysis, where analyte concentration may be low or sample mass may be small.

Some Gaussian peak shapes were observed, likely resulting from dominating diffusion processes. Higher fluences, resulting in greater mass loading, increased the occurrence of peaks with a Gaussian shape. However, the extent of this could not be fully investigated due to the saturation of the detector at fluences above $22.1 \mathrm{~J} \cdot \mathrm{cm}^{-2}$. Future work will include the development of a new data acquisition board with improved time resolution and a higher detector saturation point, such that larger mass loads and their effect on peak shape can be investigated. Due to the ease of which the DCI can be modified, the system will also be demonstrated on other ICP-MS instruments for a variety of different elements.

The data presented here were obtained on a prototype system constructed in our laboratory. As such, it almost certainly did not meet fully the design concept of a continuous, straight flow path, free from misalignments or burrs and with the central injector exactly concentric to the outer injector. Given this caveat, the data are excellent and suggest that the concept is robust and has scope for further improvement with a fully engineered version.

\section{ASSOCIATED CONTENT}

\section{Supporting Information}

Additional details of fluid modeling through CAD geometry: Table S-1 Refinement criteria and number of cells; Figure S-1, schematic diagram of the CAD generated mesh; Figure S-2, flow trajectories of the calculated gas dynamics around the micro inner Sniffer cell. This material is available free of charge via the Internet at http://pubs.acs.org.

\section{AUTHOR INFORMATION}

\section{Corresponding Author}

* B.L.Sharp@lboro.ac.uk

\section{Present Addresses}

†Inorganic Analysis, Science and Innovation, LGC Group, Queens Rd, Teddington, Middlesex, UK, TW11 0LY

\section{Author Contributions}


The manuscript was written through contributions of all authors. / All authors have given approval to the final version of the manuscript. / $\ddagger$ These authors contributed equally.

\section{ACKNOWLEDGMENT}

The authors would like to thank Matthew S.A. Horstwood (British Geological Survey); Rob Franks (University of California); David Hinds, Julian Wills, Torsten Lindemann and Lothar Rottman (Thermo Fisher Scientific); Jay Wilkins, Robert Hutchinson and Ciaran O’Connor (ESI) and Detlef Günther (ETH Zürich) for their support during either development of the interface or with ideas for inclusion in writing this article. The authors also wish to thank Andrew Bushell and Sheldon Edwards (University of Oxford) for preparation of the gadolinium labelled cell samples. Thanks to ESI, NewWave Research Division for loan of a laser system and Glass Expansion for manufacture of components. This work was completed with funding from the DIAMOND (Decommissioning, Immobilisation and Management Of Nuclear waste for Disposal) University Consortium and the European Union Seventh Framework Program (“The ONE Study”, 260687).

\section{CONFLICT OF INTEREST}

The authors declare a conflict of interest as the technology described within this article is in patent application and has been licensed by Loughborough University to ESI, Bozeman, USA.

\section{REFERENCES}

(1) Becker, J. S.; Matusch, A.; Wu, B. Anal. Chim. Acta 2014, 835, 1-18.

(2) O’Reilly, J.; Douglas, D.; Braybrook, J.; So, P.-W.; Vergucht, E.; Garrevoet, J.; Vekemans, B.; Vincze, L.; Goenagainfante, H. J. Anal. At. Spectrom. 2014, 29, 1378-1384.

(3) Šelih, V. S.; Van Elteren, J. T. Anal. Bioanal. Chem. 2011, 401, 745-755.

(4) Urgast, D. S.; Feldmann, J. J. Anal. At. Spectrom. 2013, 28, 1367-1371.

(5) Qin, Z.; Caruso, J. a; Lai, B.; Becker, J. S.; Matusch, A. Metallomics 2011, 3, 28-37.

(6) Chughtai, K.; Heeren, R. M. a Chem. Rev. 2010, 110, 3237-3277.

(7) Managh, A. J.; Hutchinson, R. W.; Riquelme, P.; Broichhausen, C.; Wege, A. K.; Ritter, U.; Ahrens, N.; Koehl, G. E.; Walter, L.; Florian, C.; Schlitt, H. J.; Reid, H. J.; Geissler, E. K.; Sharp, B. L.; Hutchinson, J. A. J. Immunol. 2014, 193, 2039-2040.

(8) Managh, A. J.; Edwards, S. L.; Bushell, A.; Wood, K. J.; Geissler, E. K.; Hutchinson, J. A.; Hutchinson, R. W.; Reid, H. J.; Sharp, B. L. Anal. Chem. 2013, 85, 10627-10634.

(9) Giesen, C.; Waentig, L.; Mairinger, T.; Drescher, D.; Kneipp, J.; Roos, P. H.; Panne, U.; Jakubowski, N. J. Anal. Atomic Spectrom. 2011, 26, 2160-2165.

(10) Drescher, D.; Giesen, C.; Traub, H.; Panne, U.; Kneipp, J.; Jakubowski, N. Anal. Chem. 2012, 84, 9684-9688.

(11) Böhme, S.; Stärk, H.-J.; Meißner, T.; Springer, A.; Reemtsma, T.; Kühnel, D.; Busch, W. J. Nanopart. Res. 2014, 16, 2592.

(12) Crayton, S. H.; Elias, D. R.; Zaki, A. Al; Cheng, Z.; Tsourkas, A. Biomaterials 2012, 33, 1509-1519.

(13) Pointurier, F.; Pottin, A.; Hubert, A. Anal. Chem. 2011, 83, 7841-7848.

(14) Varga, Z. Anal. Chim. Acta 2008, 625, 1-7.

(15) Hutchinson, R. W.; Cox, A. G.; McLeod, C. W.; Marshall, P. S.; Harper, A.; Dawson, E. L.; Howlett, D. R. Anal. Biochem. 2005, 346, 225-33.
(16) Wang, H.-J.; Wang, M.; Wang, B.; Meng, X.-Y.; Wang, Y.; Li, M.; Feng, W.; Zhao, Y.-L.; Chai, Z.-F. J. Anal. At. Spectrom. 2010, 25, 328-333.

(17) Matusch, A.; Becker, J. S. Biomed. Spectrosc. Imaging 2012, 1, 57-65.

(18) Matusch, A.; Depboylu, C.; Palm, C.; Wu, B. Höglinger, G.U., Schäfer, M. K., Becker, J.S., J. Am. Soc. Mass Spectrom. 2010, $21,161-171$.

(19) Hare, D.; Reedy, B.; Grimm, R.; Wilkins, S.; Volitakis, I.; George, J. L.; Cherny, R. a; Bush, A. I.; Finkelstein, I.; Doble, P.; Finkelstein, D. I. Metallomics 2009, 1, 53-58.

(20) Konz, I.; Fernández, B.; Fernández, M. L.; Pereiro, R.; González-iglesias, H.; Coca-prados, M.; Sanz-medel, A. Anal. Bioanal. Chem. 2014, 406, 2343-2348.

(21) M-m, P.; Merle, U.; Weiskirchen, R.; Becker, J. S. Int. J. Mass Spectrom. 2013, 354-355, 281-287.

(22) Bleiner, D.; Günther, D. J. Anal. At. Spectrom. 2001, 16, 449-456.

(23) Plotnikov, A.; Vogt, C.; Wetzig, K. J. Anal. At. Spectrom. 2002, 17, 1114-1120.

(24) Plotnikov, A.; Vogt, C.; Wetzig, K.; Kyriakopoulos, A. Spectrochim. Acta B 2008, 63, 474-483.

(25) Van Malderen, S. J. M.; Van Elteren, J. T.; Vanhaecke, F. Anal. Chem. 2015, 87, 6125-6132.

(26) Ou, K.; Hutchinson, R.; Wilkins, J.; Hilliard, S.; Summerfield, L.; O’Connor, C. In Goldschmidt; Sacramento, California, 2014.

(27) Ou, K.; Hutchinson, R. W.; O’Connor, C. In Goldschmidt; Sacramento, California, 2014

(28) Gutiérrez-González, A.; González-Gago, C.; Pisonero, J.; Tibbetts, N.; Menéndez, A.; Vélez, M.; Bordel, N. J. Anal. At. Spectrom. 2014.

(29) Müller, W.; Shelley, M.; Miller, P.; Broude, S. J. Anal. At. Spectrom. 2009, 24, 209-214.

(30) Gurevich, E. L.; Hergenröder, R. J. Anal. At. Spectrom. 2007, 22, 1043-1050.

(31) Monticelli, D.; Gurevich, E. L.; Hergenröder, R. J. Anal. At. Spectrom. 2009, 24, 328-335.

(32) Feldmann, I.; Koehler, C. U.; Roos, P. H.; Jakubowski, N. J. Anal. At. Spectrom. 2006, 21, 1006-1015.

(33) Horstwood, M. S. A.; Foster, G. L.; Parrish, R. R.; Noble, S. R.; Nowell, G. M. J. Anal. At. Spectrom. 2003, 18, 837-846.

(34) Fricker, M. B.; Kutscher, D.; Aeschlimann, B.; Frommer, J.; Dietiker, R.; Bettmer, J.; Günther, D. Int. J. Mass Spectrom. 2011, 307, 39-45.

(35) Liu, Y.; Hu, Z.; Yuan, H.; Hu, S.; Cheng, H. J. Anal. At. Spectrom. 2007, 22, 582-585.

(36) Pisonero, J.; Fliegel, D.; Günther, D. J. Anal. At. Spectrom. 2006, 21, 922-931.

(37) Lindner, H.; Autrique, D.; Pisonero, J.; Günther, D.; Bogaerts, A. J. Anal. At. Spectrom. 2010, 25, 295-304.

(38) Autrique, D.; Bogaerts, A.; Lindner, H.; Garcia, C.; Niemax, K. Spectrochim. Acta B 2008, 63, 257 - 270.

(39) Lindner, H.; Autrique, D.; Garcia, C. C.; Niemax, K.; Bogaerts, A. Anal. Chem. 2009, 81, 4241-4248.

(40) Wang, H. A. O.; Grolimund, D.; Giesen, C.; Borca, C. N.; Shaw-stewart, J. R. H.; Bodenmiller, B.; Günther, D. Anal. Chem. 2013, 85, 10107-10116.

(41) Van Malderen, S. J. M.; Van Elteren, J. T.; Vanhaecke, F. J. Anal. At. Spectrom. 2015, 30, 119-125.

(42) Sharp, B. L.; Douglas, D. N.; Managh, A. J.; Craig, G.; Reid, H. J. In The European Winter Conference on Plasma Spectrochemistry; Krakow, Poland, 2013.

(43) Liu, X. R.; Horlick, G. Spectrochim. Acta B 1994, 50, 537548.

(44) Liu, X. R.; Horlick, G. J. Anal. At. Spectrom. 1994, 9, 833- 
(45) Tanner, M.; Günther, D. J. Anal. At. Spectrom. 2005, 20, 987-989.

(46) Tanner, M.; Günther, D. J. Anal. At. Spectrom. 2007, 22, $1189-1192$.

(47) Tanner, M.; Günther, D. Anal. Bioanal. Chem. 2008, 391, 1211-20.

(48) Sharp, B. L.; Douglas, D. N.; Managh, A. J. LASER ABLATION CELL AND TORCH SYSTEM FOR A COMPOSITIONAL ANALYSIS SYSTEM, WO2014127034, US2014227776 (A1, 2014-08-14) February $14^{\text {th }} 2013$.

(49) Bleiner, D., Bogaerts, A., J. Anal. At. Spectrom. 2006, 21, $1161-1174$

(50) O’Connor, C.; Sharp, B. L.; Evans, P. J. Anal. At. Spectrom. 2006, 21, 556.

(51) Flamigni, L.; Koch, J.; Günther, D. J. Anal. At. Spectrom. 2014, 29, 280-286.

(52) Asogan, D.; Sharp, B. L.; O’Connor, C. J. P.; Green, D. A.; Wilkins, J. J. Anal. At. Spectrom. 2011, 26, 631-634.

(53) DSS, SolidWorks Flow Simulation 2012 Technical Reference, Dassault Systems 2011.

(54) Kuhn, H.-R.; Guillong, M.; Günther, D. Anal. Bioanal Chem. 2004, 378, 1069-1074.

(55) Shigeta, K.; Traub, H.; Panne, U.; Okino, A.; Rottmann, L.; Jakubowski, N. J. Anal. At. Spectrom. 2013, 28, 646-656.

(56) Lindner, H.; Bogaerts, A. Spectrochim. Acta B 2011, 66, 421-431.

(57) Lindner, H.; Murtazin, A.; Groh, S.; Niemax, K.; Bogaerts, A. Anal. Chem. 2011, 83, 9260-9266.

(58) Lan, K.; Jorgenson, J. W. J. Chromatogr. A 2001, 915, 1 13.

(59) Bogaerts, a Spectrochim. Acta B 2003, 58, 1867-1893.

(60) Zhigilei, L. V; Leveugle, E.; Garrison, B. J.; Yingling, Y. G.; Zeifman, M. I. Chem. Rev. 2003, 103, 321-48.

(61) Hergenroder, R. Spectrochim. Acta B 2006, 61, 284-300.

(62) Günther, D. ETH Zürich, CH, Personal Communication. 
For TOC purposes only:

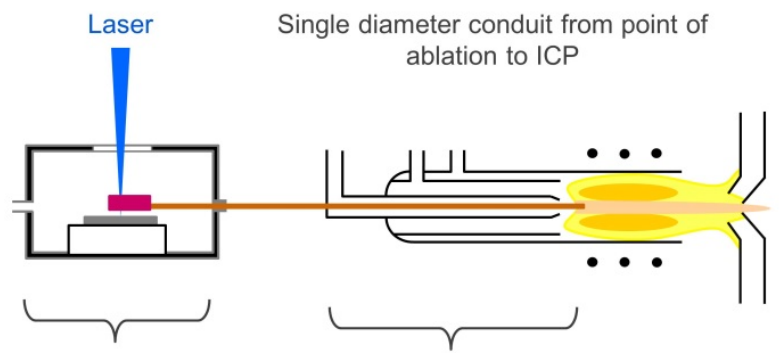

Two-volume LA cell Dual Concentric Injector 